\title{
A Path Tracking Method for Autonomous Rice Drill Seeder in Paddy Fields
}

\author{
Yan Zhang , Yanming Li, Yixiang Huang, Xiangpeng Liu, Chengliang Liu \\ School of Mechanical Engineering, Shanghai Jiao Tong University, Shanghai, China
}

\begin{abstract}
For the purpose of overcoming the obstacles in application of autonomous rice drill seeder in paddy fields, a path tracking algorithm with high accuracy used for steering control during straight traveling in uneven muddy paddy fields is introduced in this paper. Combining lateral deviation and heading angle deviation as feedback, a nonlinear steering control model is developed in the algorithm. To avoid the position error caused by incline, the influence brought by the roll angle and the pitch angle of the vehicle on position coordinates are taken into account when the vehicle is on a slant. The experiments carried out in arable paddy fields show that the mean absolute lateral deviation of the algorithm was less than 2.9 centimeters and the heading angle deviation was less than $0.03^{\circ}$. The path tracking algorithm is able to meet the required precision for autonomous rice drill seeder in paddy fields of China.
\end{abstract}

\section{Introduction}

Precision agriculture has been significantly developed in recent years thanks to advances in mechanization and automation. As a result, lower production costs, less reliance on manual labour and more reliable quality of crops turn into reality with the use of automated agriculture machines [1]. One of the key features of automated agriculture machines is the automatic guidance. Auto-guidance system enables agricultural machines to work on the defined path automatically without drivers controlling the steering wheel anymore. In addition, drivers will feel tired after driving for several hours, resulting in the increment of lateral deviation of path tracking, while auto-guidance machines are capable of completing the task more accurately during long periods of work and will never get exhausted [2]. Therefore, automatic guidance of agricultural machines has been a hot spot recently and gets motivated with the development of computer and sensor technology [3].

Autonomous vehicles were able to move to a specified place by itself with the help of various sensors and multiple systems in the DARPA Grand Challenge and the Urban Challenge [4]. Some cars can run for a while independent of driver's attention [5]. Safety is the most important issue instead of tracking error for vehicles on road. Moreover, current autonomous vehicles are not designed to work in padding fields. But in the field of agricultural robotics, agricultural machines are always working under unstructured environment and tracking error is one of the key issues we concern. However, high accuracy path tracking is a challenging task for rice drill seeder in paddy fields due to uneven grounds as well as muddy soil conditions.
PID control and single parameter control are the most used algorithm in autonomous agricultural navigation. In General, the controlled variable is the wheel steering angle [6-7]. Steering controllers based on the PID method were implemented by some researchers [8-11]. But the experiment conducted showed a large overshoot and the precision was not satisfying. Zhang and Qiu proposed a dynamic path search algorithm for an autonomous agricultural tractor to track the desired path [12]. With both tractor dynamics and path-tracking error taken into consideration, the test on asphalt and farm fields showed that the lateral deviation was less than $0.1 \mathrm{~m}$ on straight segments and less than $0.8 \mathrm{~m}$ at end-row turn segments. However, they mentioned neither if the farm field is uneven or muddy or how to guarantee the accuracy when the tractor is on a slant. Han et al. offered a tracking algorithm with acceptable accuracy for a Korean autoguidance Tillage Tractor. The steering angle is obtained by comparing the heading angle of the vehicle with the waypoints angle in the algorithm [13]. Control algorithms based on PID or Fuzzy are the simplest methods applied to autonomous agricultural path tracking when the mathematic model of accurate steering system is unable to obtain [14-15]. However, the performance of PID controllers is not very robust when applied to a nonlinear system [16]. Artificial Neural Network (ANN) were designed by Ganapathy et al. to control the autonomous mobile robot for wall-following [17]. But ANN places a greater demand on computers, as real-time calculation of ANN is a hard task for most embed computers. Javad et al. designed a nonlinear controller for accurate path following [18]. The simulation showed that the rms (Root Mean Square) position offset was $1.36 \mathrm{~cm}$ and the $\mathrm{rms}$ heading angle error was $1.65^{\circ}$. However, the nonlinear controller was not tested in fields. 
This study aimed at presenting a high accuracy path tracking algorithm of rice drill seeder in uneven paddy fields. To that end, a reliable approach with incline taken into consideration to avoid effects on path tracking accuracy when the tractor is on a slant is illustrated in detail. Additionally, a steering control law was developed to achieve high accuracy. Experiments in uneven paddy fields verified the accuracy of the algorithm in this study.

\section{Kinematic modeling}

A kinematic model was applied to describe the agricultural vehicle motion in Cartesian coordinates space in this paper. By the assumptions that the vehicle moves at a low constant speed over an ideal ground and slipping only affects the front wheels, the kinematic model of the agricultural vehicle is simplified as a bicycle model. As shown in figure 1 , the vehicle is simplified as a bicycle shape in the derivation of the kinematic model. The front axle, where the steering wheels are, is considered as a single wheel. The rear axle is considered as a single wheel in the same way. The parameters and notations used in this model are listed in table 1.

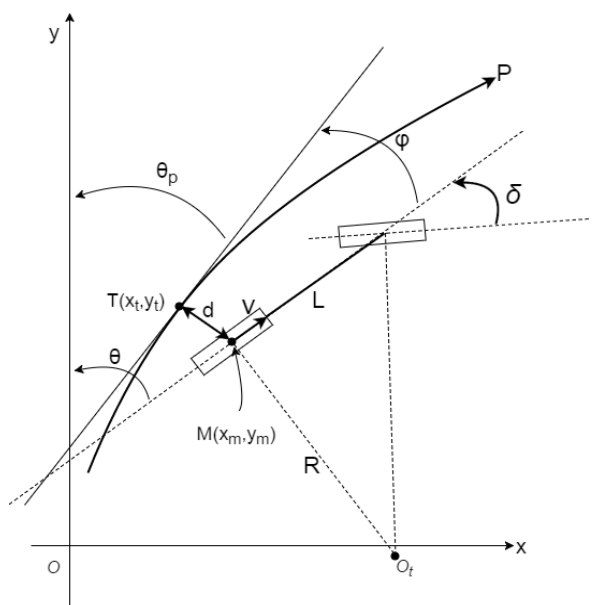

Figure 1. Kinematic model and parameters of the vehicle.

Table 1. The symbols and parameters in the kinematic model.

\begin{tabular}{|c|c|}
\hline Item & Description \\
\hline$\delta$ & $\begin{array}{l}\text { front wheel steering angle and the sole control } \\
\text { variable. }\end{array}$ \\
\hline$\omega$ & steering rate. \\
\hline$\theta$ & heading angle. \\
\hline$L$ & vehicle wheelbase. \\
\hline$x, y$ & $\begin{array}{l}\text { coordinates of the center position of the rear axle } \\
\text { center. In addition, the y direction is coincident } \\
\text { with the true north. }\end{array}$ \\
\hline$v$ & realized vehicle linear velocity. \\
\hline$P$ & path to be followed. \\
\hline$d$ & lateral deviation. \\
\hline$\varphi$ & heading angle deviation. \\
\hline$R$ & turning radius of rear wheel. \\
\hline$M$ & $\begin{array}{l}\text { mid point of rear axle of the vehicle, whose } \\
\text { coordinates are } x_{m} \text { and } y_{m} \text {. }\end{array}$ \\
\hline$T$ & $\begin{array}{l}\text { the closest point to } \mathrm{M} \text { on the path } \mathrm{P} \text {, whose } \\
\text { coordinates are } \mathrm{xt} \text { and } \mathrm{yt} \text {. }\end{array}$ \\
\hline
\end{tabular}

The derivative of $\theta$ is given as equation below:

$$
\begin{gathered}
\theta=\frac{v}{R} \\
R=\frac{L}{\tan \delta}
\end{gathered}
$$

Combine (1) with (2), and the derivative of $\theta$ is:

$$
\theta=\frac{v \tan \delta}{L}
$$

The derivative of $x$ is:

$$
\dot{x}=v \cos \theta
$$

The derivative of $\mathrm{y}$ is:

$$
\ddot{y}=v \sin \theta
$$

So the kinematic model of the agricultural vehicles is given as follows:

$$
\left[\begin{array}{l}
\dot{x} \\
\dot{y} \\
\theta \\
\dot{\delta}
\end{array}\right]=\left[\begin{array}{c}
v \cos \theta \\
v \sin \theta \\
\frac{v \tan \theta}{2} \\
0
\end{array}\right]+\left[\begin{array}{l}
0 \\
0 \\
0 \\
1
\end{array}\right] \omega
$$

And the motion state of vehicle can be defined as the fourth-order vector:

$$
s=[x, y, \theta, \delta]
$$

\section{Control methods}

The desired traveling path was planned by the controller before a path tracking task began. The path tracking algorithm can be split into two parts, the position compensation algorithm and the steering control algorithm.

\subsection{Position compensation algorithm}

Running on the ground that is uneven and rough is troublesome to get the accurate position of point $\mathrm{P}$ (figure 1) from global position system (GPS) whose sensor is installed on top of the vehicle because the absolute coordinates of $\mathrm{P}$ will be affected when the vehicle tips on the uneven ground and the projection point on the ground of GPS sensor is not coincident with that of P. The effects can be split into two groups. One is the roll effect, which results in lateral position error of $\mathrm{P}$. Another is the pitch effect, which results in longitudinal position error of $P$.

Suppose that the mounting height of GPS sensor is $H$, roll angle of the vehicle body is $\varphi$, and the pitch angle is $\psi$. As shown in figure 2, the roll effect is given as $e_{l a}$ :

$$
e_{\text {lat }}=H \sin \varphi
$$

The pitch effect is given as $e_{l o n}$ :

$$
e_{\text {lon }}=H \sin \psi
$$

Hence the coordinates of $\mathrm{P}$ can be corrected with the equations given below:

$$
\left\{\begin{array}{l}
x_{m}=x_{m}^{\prime}+H \sin \varphi \cos \theta-H \sin \psi \sin \theta \\
y_{m}=y_{m}^{\prime}+H \sin \varphi \sin \theta+H \sin \psi \cos \theta
\end{array}\right.
$$




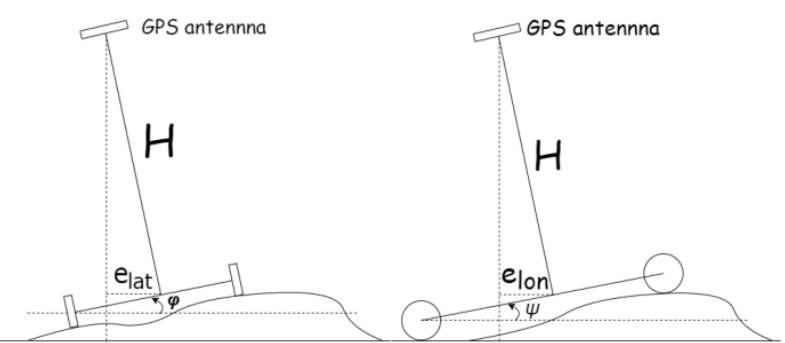

Figure 2. Position errors caused by incline.

In equation(10), $\left(x_{m}, y_{m}\right)$ are the modified coordinates of $M$, while $\left(x_{m}^{\prime}, y_{m}^{\prime}\right)$ is the coordinates given by the GPS sensor. And $\theta$ is the heading angle.

\subsection{Steering control algorithm}

The lateral deviation from the desired path was denoted as $d$, which can be derived by the follow equation:

$$
d=\sqrt{\left(x_{m}-x_{t}\right)^{2}+\left(y_{m}-y_{t}\right)^{2}}
$$

In equation(11), $\left(x_{m}, y_{m}\right)$ are the coordinates of $M$, and $\left(x_{t}, y_{t}\right)$ are the coordinates of $T$.

Assuming that $\theta_{p}$ is the heading angle of the tangent to path $P$ at point $T$ and $\theta$ is the heading angle, the heading angle deviation $\varphi$ is shown in equation(12):

$$
\varphi=\theta_{p}-\theta
$$

The steering control algorithm is given by (13) as follows:

$$
\delta=\varphi+\arctan \frac{k(d-L \sin \theta)}{v}+k_{i} I_{\text {int }}
$$

In equation(13), $I_{\text {int }}$, which is employed to eliminate the steady-state errors, is the integral of $d$. $L$ denotes the vehicle wheelbase, and $v$ represents the realized vehicle linear velocity. The steering control parameters $\left(k_{i}\right.$ and $\left.k\right)$ were obtained experimentally. The value of $k$ is set to 1.3 and $k_{i}$ is set to 0.5 in this study.

\section{Field experiments}

The platform used for path tracking experiments was a YANMAR Model VP6E rice drill seeder. Model VP6E is a four-wheel tractor which turns around with front wheel steering, manufactured by YANMAR Corporation (Osaka, Japan). The vehicle wheelbase of the rice drill seeder is $1.09 \mathrm{~m}$, and the vehicle linear velocity of the tractor was set to $0.7 \mathrm{~m} / \mathrm{s}$. Significant modifications were made to the rice drill seeder for the automation tasks. A geared step-motor that outputs 6-Nm torque was attached to the steering column. As the primary torque was too low for the steering, the motor output was fed through a 2:1 speed down gear. At last, the motor outputs $12-\mathrm{Nm}$ torque on the steering rack. The rice drill seeder was equipped with an RTK-GPS system, whose antenna is located on the top of the tractor cabin for position determination. An inclinometer was installed on the tractor cabin to obtain the pitch angle and the roll angle, which are subsequently employed to compensate the position errors of the tractor. An absolute rotary encoder was connected to the steering axle to obtain the steering angle. The accelerator was connected to an electric putter with a cable for speed control. A single board with an 800MHz ARM Cortex-A8 processer (AM335X, TEXAS INSTRUMENTS, USA) was selected as the host computer, which communicates with all sensors and slave computers via $\mathrm{CAN}$ and serial ports.

Field experiments were conducted in an uneven paddy filed $(100 \mathrm{~m} \times 30 \mathrm{~m})$. Path tracking experiments were performed along the longer side of the field. The desired traveling path was planned as parallel straight lines with a distance of $2.5 \mathrm{~m}$ away from each other in advance of the experiments. Figure 3 shows the entire recorded path of the rice drill seeder. In this figure, the experiment started at the upper-right corner.

Table 2 shows the summary of the performance of the path tracking algorithm in the field experiments. The rms lateral deviation from the desired path was observed to be less than $0.05 \mathrm{~m}$, and the heading angle rms error was no more than 2.6 degrees. The mean absolute lateral deviation of each path was less than $0.04 \mathrm{~m}$. The mean absolute heading angle error was observed to be less than 0.04 degrees.

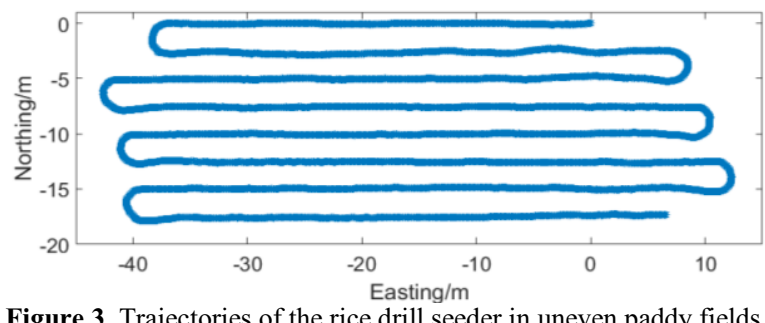

\begin{tabular}{|c|c|c|c|c|c|}
\hline \multirow[b]{2}{*}{$\begin{array}{l}\text { Path } \\
\text { No. }\end{array}$} & \multicolumn{5}{|c|}{ Lateral deviation $(\mathrm{m})$} \\
\hline & Max & Min & $\begin{array}{c}\text { Mean } \\
\text { Absolute }\end{array}$ & rms & Std \\
\hline 1 & 0.101 & -0.109 & 0.032 & 0.044 & 0.044 \\
\hline 2 & 0.088 & -0.112 & 0.043 & 0.051 & 0.051 \\
\hline 3 & 0.082 & -0.087 & 0.033 & 0.039 & 0.039 \\
\hline 4 & 0.096 & -0.078 & 0.026 & 0.032 & 0.032 \\
\hline 5 & 0.088 & -0.087 & 0.029 & 0.036 & 0.035 \\
\hline 6 & 0.094 & -0.142 & 0.025 & 0.039 & 0.039 \\
\hline 7 & 0.112 & -0.088 & 0.021 & 0.030 & 0.029 \\
\hline 8 & 0.093 & -0.092 & 0.018 & 0.026 & 0.025 \\
\hline overall & 0.112 & -0.142 & 0.028 & 0.038 & 0.038 \\
\hline \multirow[b]{2}{*}{$\begin{array}{l}\text { Path } \\
\text { No. }\end{array}$} & \multicolumn{5}{|c|}{ Heading angle error (degree) } \\
\hline & Max & Min & $\begin{array}{c}\text { Mean } \\
\text { Absolute }\end{array}$ & $\mathrm{rms}$ & Std \\
\hline 1 & 6.32 & -3.41 & 0.03 & 1.83 & 1.82 \\
\hline 2 & 8.20 & -5.94 & 0.04 & 2.62 & 2.75 \\
\hline 3 & 5.04 & -7.07 & 0.03 & 1.96 & 1.96 \\
\hline 4 & 6.73 & -2.89 & 0.03 & 1.83 & 1.84 \\
\hline 5 & 4.68 & -7.73 & 0.03 & 2.07 & 2.07 \\
\hline 6 & 7.58 & -5.08 & 0.02 & 2.10 & 2.07 \\
\hline 7 & 4.32 & -7.03 & 0.02 & 1.81 & 1.81 \\
\hline 8 & 5.96 & -1.81 & 0.02 & 1.49 & 1.46 \\
\hline overall & 8.20 & -7.73 & 0.03 & 2.02 & 2.02 \\
\hline
\end{tabular}

Figure 3. Trajectories of the rice drill seeder in uneven paddy fields.

Table 2. Summary of the performance of the algorithm. 
Table 3. Ratio of the lateral deviation less than $0.05 \mathrm{~m}$ or $0.1 \mathrm{~m}$

\begin{tabular}{ccc}
\hline Path number & $\begin{array}{c}\text { Less than } 0.05 \mathrm{~m}- \\
\text { Ratio }\end{array}$ & $\begin{array}{c}\text { Less than } \\
0.1 \mathrm{~m}-\text { Ratio }\end{array}$ \\
\hline 1 & $77 \%$ & $97.0 \%$ \\
2 & $60 \%$ & $97.4 \%$ \\
3 & $75 \%$ & $100 \%$ \\
4 & $90 \%$ & $100 \%$ \\
5 & $84 \%$ & $100 \%$ \\
6 & $85 \%$ & $95.3 \%$ \\
7 & $90 \%$ & $99.6 \%$ \\
8 & $92 \%$ & $100 \%$ \\
\hline
\end{tabular}

Table 4. The initial lateral deviations and heading angle errors at the starting points of each path.

\begin{tabular}{ccc}
\hline $\begin{array}{c}\text { Path } \\
\text { number }\end{array}$ & $\begin{array}{c}\text { Lateral deviation } \\
(\mathrm{m})\end{array}$ & $\begin{array}{c}\text { Heading angle error } \\
\text { (degree) }\end{array}$ \\
\hline 1 & 0.10 & -3.02 \\
2 & 0.09 & 7.92 \\
3 & -0.09 & -7.06 \\
4 & 0.09 & 6.73 \\
5 & -0.09 & -6.91 \\
6 & 0.09 & 5.13 \\
7 & -0.09 & -6.96 \\
8 & 0.09 & 5.74 \\
\hline
\end{tabular}
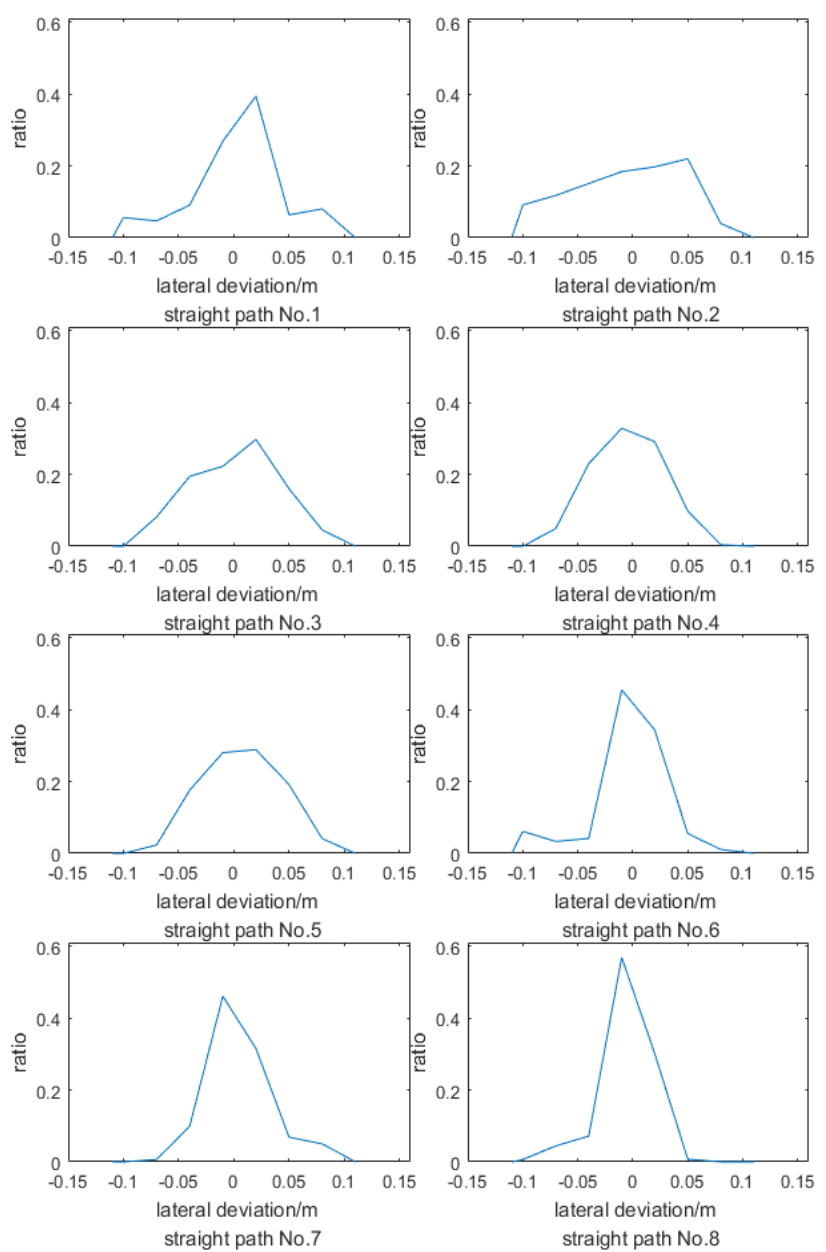

Figure 4. The frequency distribution of the lateral deviation of each path.

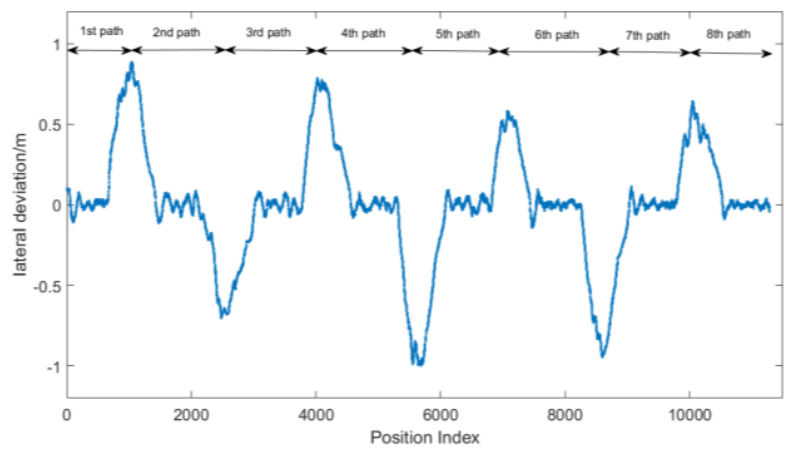

Figure 5. Lateral deviations during the test.

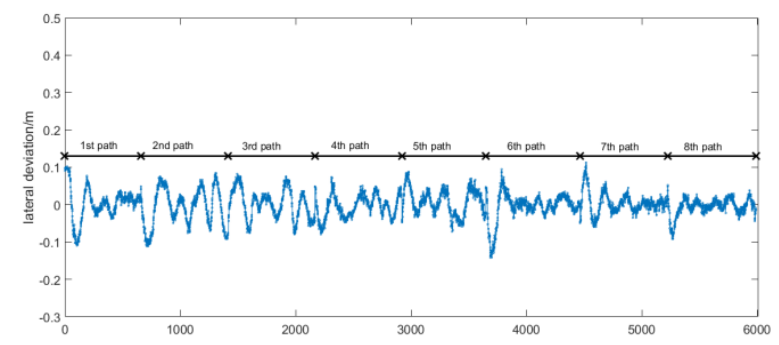

Figure 6. Lateral deviations of all straight paths.

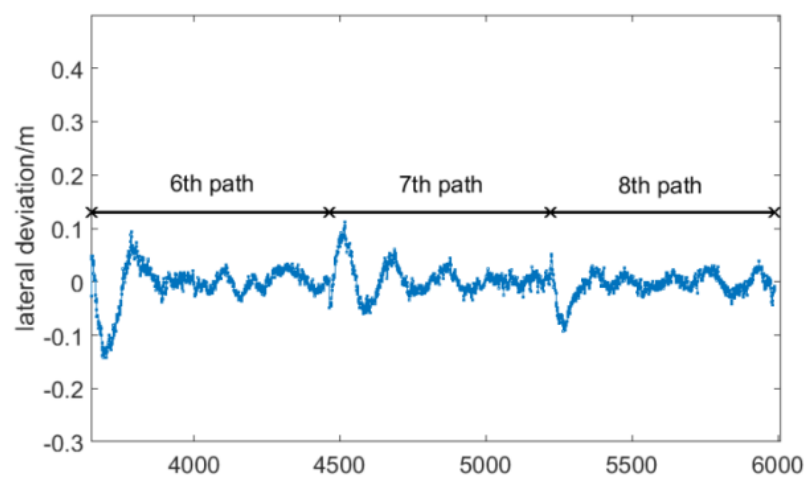

Figure 7. Lateral deviations of path No.6, No.7, No.8.

Table 3 shows that more than $60 \%$ of the measured points on the path of the rice drill seeder were located within $0.05 \mathrm{~m}$ of the desired path. As the row spacing of the rice plants is always set to $0.25 \mathrm{~m}$ in China, it was observed that more than $95 \%$ of the measured points on the travelled path were located within the $0.1 \mathrm{~m}$-range of the desired path. The lateral deviations of path $3,4,5,8$ are all less than $0.1 \mathrm{~m}$. Thus the performance of the path tracking algorithm for autonomous rice drill seeder could be good enough for agricultural automation in uneven paddy fields. Figure 4 shows the frequency distribution of the lateral deviation of each path. It was also observed that most measured points were located within the $0.05 \mathrm{~m}$ range of the desired path. Table 4 shows the initial lateral deviations and heading angle errors at the starting points of each path. Lateral deviations are all more than $0.08 \mathrm{~m}$ and heading angle errors are all more than 3 degrees.

Figure 5 shows the whole lateral deviation during all straight path tracking operations. It can be seen that the lateral deviation during straight path tracking was close to $0 \pm 0.05 \mathrm{~m}$; the lateral deviation increased to $0.9 \mathrm{~m}$ after the rice drill seeder turns back; however, the path tracking algorithm was able to decrease the lateral deviation to less than $0.05 \mathrm{~m}$ in a short distance less than $5 \mathrm{~m}$. And the 
overall mean absolute lateral deviation of all path was mere $0.028 \mathrm{~m}$. Figure 6 shows the lateral deviations of all straight paths. Most of the lateral deviations are less than $0.1 \mathrm{~m}$. Fig. 7 shows the details of the lateral deviations of path No.6, No.7, No.8.

\section{Conclusion}

A high accuracy path tracking algorithm for rice drill seeder in uneven paddy fields is presented in this paper. The effect on position measurement caused by the incline of the tractor cabin when the tractor is on a slant is investigated. The method for compensating the position errors of the tractor is developed in the proposed algorithm to improve the accuracy of path tracking. Moreover, a steering control model with feedback components and integrators is proposed to control the rice drill seeder to travel along the desired path with high accuracy. Experiments were conducted to verifythe accuracy of this algorithm. The mean absolute lateral deviation of all measured points was observed to be less than $0.029 \mathrm{~m}$ and the mean absolute heading angle deviation was less than $0.03^{\circ}$ at the speed of around $0.7 \mathrm{~m} / \mathrm{s}$ with the algorithm. The lateral deviations after the rice drill seeder turns back was observed to increase to $0.9 \mathrm{~m}$. However, the algorithm was able to decrease the lateral deviation to less than $0.05 \mathrm{~m}$ in a short distance less than $5 \mathrm{~m}$. More than $95 \%$ of the absolute values of the measured lateral deviations are less than $0.1 \mathrm{~m}$. Accordingly, the plants rows won't cross each other with the algorithm as most common row spacing of rice plants in China is $0.25 \mathrm{~m}$. Thus, the performance of the algorithm could be good enough for agricultural automation in uneven paddy fields in China [6]. To get the autonomous rice drill seeder more productive, research on high accuracy path tracking with a faster speed in paddy fields and experiments to show the advantages of autonomous rice drill seeders over those with drivers will be conducted in future works.

\section{Acknowledgements}

The research conducted in this paper is sponsored by National Key Research and Development Program of China (Grant No. 2016YFD0700500) and "Shanghai Sailing Program" (Grant No.18YF1411000).

\section{References}

1. Edan, Y., Han, S., Kondo, N., Springer Handbook of Automation. pp. 1095-1128,(2009).
2. Roland L, Benoit T, Christophe C, Philippe M, Auton Robot, 21, pp.79-97, (2006).

3. Wilson, J.N., Computers and Electronics in Agriculture, 25, pp.3-9, (2000).

4. Sebastian Thrun, Mike Montemerlo, Hendrik Dahlkamp, Journal of Field Robotics, 23, pp. 661692, (2006).

5. Babak S, Syed A, Burak K, Sabri C, IOP Conference Series: Materials Science and Engineering, 224, pp. 012029, (2017).

6. Garcia-Perez L , Garcia-Alegre M C ,Ribeiro A, et al, Computers and Electronics in Agriculture, 60 , pp. 39-48, (2008).

7. Norremarka M, Griepentrog $\mathrm{H} \mathrm{W}$,Nielsen J, et al, Biosystems Engineering, 101, pp. 396-410, (2008).

8. X. Wu, Z. Zhao, Z. Zhang, B. Chen, and L. Hu, Transactions of the Chinese Society of Agricultural Machinery, 40, pp. 1-5, (2009).

9. L. Gao, J. Hu, X. Bai, T. Li, and X. Liu, in Proceedings of the International Conference on Broadcast Technology and Multimedia Communication, pp. 315-322, (2010).

10. J. B. Derrick and D. M. Bevly, Journal of Field Robotics, 26, pp. 519-536,(2009).

11. X. Wu, Z. Zhao, Z. Zhang, L. Yu, L. Hu, and J. Huang, in Proceedings of the International Conference on Intelligent Computation Technology and Automation, pp. 294-298, (2010).

12. Zhang, Q., Qiu, H, Trans. ASAE, 47, pp. 639-646, (2004).

13. Han, X.Z., Kim, H.J., Moon, H.C., Woo, H.J., Kim, J.H., Kim, Y.J, Journal of Biosystems Engineering, 38, pp. 1-8, (2013).

14. Chu, J., Li, H., Cui, P., Qiang, T., Ruijun, L., International Research Journal of Engineering Science, Technology and Innovation, 2, pp. 57-64, (2013).

15. Li,T.C ,Hu,J.T, Mathematical Problems in Engineering, 2, pp. 1-10, (2014).

16. Hu, C., Yao, B., and Wang, Q., in Proceedings of the IEEE/ASME International Conference on Advanced Intelligent Mechatronics, pp. 1810- 1815, (2009).

17. Ganapathy V, Yun SC, and $\mathrm{Ng} \mathrm{J}$, in Proceedings of the IEEE/ASME International Conference on Advanced Intelligent Mechatronics, pp. 1236-1241, (2009).

18. Javad Taghia, Stanley Lam and Jay Katupitiya, in Proceedings of the IEEE/ASME International Conference on Advanced Intelligent Mechatronics, pp. 713-718, (2015). 